Baris BARLAS

Reyhan OZSOYSAL

Ertekin BAYRAKTARKATAL

Osman A. OZSOYSAL

http://dx.doi.org/10.21278/brod68406

\title{
A STUDY ON THE IDENTIFICATION OF FIRE HAZARDS ON BOARD: A CASE STUDY
}

UDC 629.5.067:629.5.081:629.545

Professional Paper

\begin{abstract}
Summary
The RoRo ship MS UND ADRIYATIK was wrecked in February 2008 by a catastrophic fire. The causes of the accident included a combination of human, technical and organizational factors. In this study, the authors describe the accident, its chronology, and the dependencies involved. They then examine some of the erroneous series of human's operations, design and technical errors that led to the disaster and their organizational roots at the time of the accident. Risk-reduction measures can be costly, though; priorities must be set based on costs and benefits. This research suggests ways to support fire prevention efforts. Nine possible reasons were determined to perform a survey suitable for AHP technique. The purpose of this survey is to determine the order of possible explanations for this fire accident and possible provisions and precautions to be taken.
\end{abstract}

Key words: $\quad$ Fire safety; Fire on board; AHP method; Case study.

\section{Introduction}

There is no ship which can be operated in $100 \%$ safe or error-free. Hazard identification and risk analysis is generally focused on the risk level analysis and the determination of the greatest risk points for fire on board. The analyses which will be properly carried on reduce the failure risk to a preferred level, and ensure the ship reliability in critical conditions. Hence, the risk analysis tools have been developed to ensure the system reliability in critical applications. Though profound analysis of historical accidents can help to amend the regulations, and reduce the conceptual risk without changing the real risk at all. It is important to realize that maritime safety is not only a matter of primary social importance but also has a significant commercial aspect. Indeed a perceived high level of safety constitutes a vital ingredient in the package sold by the operators to their customers.

The aims of the study can be defined as:

- Strategies to minimize the fire on board casualties especially on RoRo ships is outlined, 
- A risk framework of fire on board casualties especially on RoRo ships is drawn. In order to minimize the occurrence of casualties,

- The findings of the study suggest that variables contribute to fire on board casualties especially on RoRo ships, thus broadening the understanding of these phenomena, which can support new approaches to the prevention of fire on board.

It is a well-known fact that fire on board is one of the main ship accidents resulting in loss of life and property. Due to the complexity of fire and the uncertainties involved, if the fire on board cannot extinguish, it may lead to a disaster, total actual loss and serious casualties. The data for this case study was collected from GISIS, which is a database provided by the International Maritime Organization (IMO), which contains casualties and incidents data reported by the IMO member states. By using the IMO's GISIS: Marine Casualties and Incidents database, we have done the study of different types of ships reporting serious and very serious fire casualties starting from year 2000 [1]. Very serious fire casualties are casualties to ships which involve total loss of the ship and/or loss of life. Serious fire casualties are casualties to ships which do not qualify as "very serious fire casualties" and which involve a fire and/or explosion, resulting in: immobilization of main engines, extensive accommodation damage, severe structural damage, etc. The serious and very serious fire casualties of different types of ships from between 2000 - 2014 are given in Table 1. It is evident that the reported fire incidents on board are very noteworthy for RoRo/Ferry/Passenger ships, comparing to other types of ships. Almost one out of five reported serious and very serious fire casualties are from RoRo/Ferry/Passenger ships.

Table 1 Different types of ships reporting serious and very serious fire casualties between 2000 and 2014

\begin{tabular}{|c|c|c|}
\hline Ship Type & Casualty Number & Percentage \\
\hline Tanker & 52 & 19.1 \\
\hline RoRo/Ferry/Pass. & 52 & 19.1 \\
\hline General cargo & 40 & 14.7 \\
\hline Fishing Vessel & 37 & 13.6 \\
\hline Bulk/Ore Carrier & 32 & 11.8 \\
\hline Others & 28 & 10.3 \\
\hline Container & 24 & 8.8 \\
\hline Tug/Supply & 7 & 2.6 \\
\hline
\end{tabular}

RoRo/Ferry/Passenger ships have been causing $19.1 \%$ of marine casualty in the world between 2000 and 2014. But someone should consider it not the occurring number, but the incidence rate. In Table 2, the average incidence rates of different types of ships reporting serious and very serious fire casualties between 2000 and 2014 is given. Average incidence rate refers to the number of fire casualties per 1,000 ships in 15 years period. It is calculated by dividing the casualty numbers by average number of ships. The average number of ship data are obtained from different sources, and gives an estimate value. The average incidence rate of fire casualties between the years 2000 and 2014 in RoRo/Ferry/Passenger ships is 6.58. This means that, on average, every 1000 RoRo/Ferry/Passenger ships, 6.58 of them reported 
serious and very serious fire casualties. During the same period, all other ship groups' average incidence rate is 3.24. As a result, the RoRo/Ferry/Passenger ships incidence rate is two times higher than the average of all other ship groups.

Table 2 The incidence rates of different types of ships reporting serious and very serious fire casualties between 2000 and 2014

\begin{tabular}{|c|c|c|}
\hline Ship Type & Average Incidence Rate & Average Number of Ships \\
\hline RoRo/Ferry/Pass & 6.58 & 7907 \\
\hline Container & 4.83 & 4974 \\
\hline Tanker & 3.70 & 14068 \\
\hline Bulk/Ore Carrier & 3.33 & 9597 \\
\hline General cargo & 2.31 & 17284 \\
\hline Fishing Vessel & 1.61 & 23000 \\
\hline Tug/Supply & 0.34 & 20802 \\
\hline
\end{tabular}

There are various articles in the literature regarding marine casualties and incidents [2, 3]. On the maritime accidents background Hassel et al. gives a comprehensive review [4]. Macrae investigated the common patterns of human and organizational causes underlying groundings and collisions [5]. Arslan and Turan examined the factors which affect marine casualties with using SWOT analysis, then weighting of the factors determined by using the AHP method [6]. With their approach, strategic action plans were developed for minimizing shipping casualties. Kang et al. studied the marine casualties, especially the collision and the machine damage, in Korea [7]. They suggested that, it is necessary for the seafarer to take more education and training, especially for the crews of fishing vessels. Schröder-Hinrichs et al. investigated the accident reporting deficiencies related to organizational factors in machinery space fires and explosions by analysing 41 accident investigation reports [8]. Dutta and Kar investigated the simulation techniques for ship on board fire safety [9]. Wang and $\mathrm{Su}$ investigated the distribution of smoke with iso-concentration and the height of smoke layer of a ship engine room, and they suggested improvements for research of fires in ships [10].

In general, before spreading out to other spaces initial source of fire is mostly located in confined spaces, like cargo area, engine room and accommodation area. Any malfunctions of ship's auxiliary systems easily leads to an availability of fire, in addition, with regard to accommodation area generally fire breaks out due to malfunctions of electrical equipment. Cargo area, in general, is another space that dangerous cargoes could be the reason for on board fire. Although, fire detection, suppression and containment arrangements on board are widely provided, but sometimes the systems could not work properly because of malfunction or human factors involved.

This paper investigates the marine fires with exercising a specific example, MS UND ADRIYATIK fire and examine why and how the fire could not be controlled nor extinguished. Nine possible reasons were determined to perform a survey suitable for Analytic Hierarchy Process (AHP) technique. Twenty-six experts were surveyed across the four areas that included sea captains, chief engineers, technical and P\&I Club surveyors, and safety engineers. The purpose of this survey is to determine the order of possible explanations for this fire accident and possible provisions and precautions to be taken. 


\section{Materials and methods}

The MS UND ADRIYATIK was a RoRo ship. She was 193 meters in length, and has a capacity of 3214 lane meters on four decks. She was the fourth ship in a series of six, built in Flensburger Schiffbau Gesellschaft shipyard in Germany. She went into service in 2001. She was used for transporting goods between Istanbul, Turkey and Trieste, Italy. MS UND ADRIYATIK caught fire on the early morning hours of February 6, 2008, 13 nautical miles off the coast of Istria, Croatia, just outside Croatian territorial waters. An SOS was launched. It said that the ship was sailing from Istanbul to Trieste and was carrying 200 trucks and nine tons of dangerous material, in addition to between 100 and 200 tons of ship fuel, causing fears of environmental damage. Then, the ship's 22 crew members and nine passengers were rescued by the Greek ship Ikarus Palace that was sailing nearby.

\subsection{Progress of events}

The progress of events is abstracted from independent expertise reports, witness statements and court papers. MS UND ADRIYATIK departed from its terminal in Istanbul on 03 February 2008 to her destination Trieste with 22 crew and 9 truck drivers on board. She carried 200 trucks and trailers, which were stowed and secured in her 4 decks. Trucks carrying International Maritime Dangerous Goods (IMDG) Code Class 4.1 and 3 type dangerous cargoes were stowed on the upper deck in accordance with certificate for carriage of dangerous goods [11]. Neither the vehicles with refrigeration plants were stowed in the closed decks. Trucks with electrically-driven refrigeration plants were stowed at upper deck, and trucks with separate diesel engine used to driven reefer units were stowed at top deck. There were no particular ignition sources to start a fire in cargo decks other than the trucks and the trailers. There were about 60 trucks and trailers on the main deck, all of them with batteries, diesel fuel, flammable objects, butane/propane canisters and stoves for cooking etc. After departing from terminal, as a standard procedure, the outer ventilation and ventilation dampers were closed. The voyage was ordinary until about 05:30 hours in the early morning of 06 February 2008, just 3 hours before arrival at her arranged destination port of Trieste.

The chief officer started his watch on 04:00 hours as usual. There was also a watchman at the bridge. The weather was N/NE 3 Beaufort, sea state was 2 and visibility was good. Steering gear was in automatic pilot mode. At around 05:30 hours, a fire alarm went on by the automatic fire detection system, and the fire detecting and alarm system panel on the bridge indicated the fire at the $14^{\text {th }}$ and $15^{\text {th }}$ smoke detector loops for main deck. The smoke detectors denoted the fire signals coming from the vehicle ramp at the port side of main deck through the upper deck. The mentioned section was controlled by the Deluge Sprinkler system. A Deluge Sprinkler system is a fixed fire protection system in which the pipe system is empty until the deluge valve operates to distribute pressurized water from sprinklers. The chief officer silenced the alarm. When the alarm is in silenced mode, the lights stay on for the zones but the sound is off. The chief officer needs to check if the alarm is real or fake, and he reset the alarm system. Alarms system immediately reproduced the fire alarm signal after resetting. The chief officer described the fire zone to the watchman near him and directed him to check the position of fire on the main deck. The chief officer then reset the alarm system for the second time while waiting the watchman and he noticed the alarm signal was still sounding. The chief officer called the bosun (a ship's officer in charge of equipment and the crew) by phone and sent him to control the fire zone.

The watchman went down to the main deck through the stairs in the accommodation area and opened the watertight door with the help of the bosun which is kept closed all the time during the journey. The crew entering the main deck area saw that the trucks parked on 
the second and third lanes on the port side were burning and visibility due to heavy smoke was too short. The bosun reported the fire on the main deck by phone to the chief officer, then both the bosun and the watchman left the fire area immediately as they were not equipped with any protective of firefighting equipment. Then, the chief officer immediately waked up the Captain, and the Captain arrived at the bridge shortly afterwards, the time was 05:48, the general alarm was activated. The chief officer informed all on board with two announcements from the ship announcing system and called them to summon on the muster-station (the place on the ship where crew should assemble in the event of an emergency) to fight the fire. The Captain transmitted a distress call by VHF radio at 06:04.

The firefighting team finalized their preparations about 7 minutes and went down to the watertight door of the main deck, however, only two seafarer could just be equipped with firefighting suits, the other crew members had no protective equipment. Several minutes were lost during the preparation of the life safety rope. Afterwards, the machinery and deck teams entered into the fire scene. Team who took the fire hose proceed into the fire scene for about 5 to 10 meters under conditions of thick smoke. The fire hose puffed-up but air was discharging instead of water. No water was coming from the hose. The team noticed that the second and third trucks just from the sliding door towards the fore-port part was in flames. The smoke was getting thicker and a panic was growing by the time. Afterwards the Captain at the bridge ordered to the third officer to start the sprinkler pump and the emergency fire pump right after the report from the firefighting team. But this was another non-useful solution just like the fire hose trial, because the water was not sprayed from the sprinklers. The firefighting team members without protective equipment were badly affected. After a while, the firefighting team members figured out that it was of no use without water and decided to leave the scene, failed to control and extinguish the fire.

Fire, heat and smoke in the aft upper deck blocked access to lifeboats and all were trapped in the bridge area. They managed to escape to the forecastle by descending down from the forward wall of accommodation using fire hoses and flag lanyards. After 15 minutes, the Captain had to give the order to abandon the ship as the fire approached dangerously close. All crew and truck drivers were rescued by about 07:00. The starting location of the fire is depicted in Fig. 1 [12].
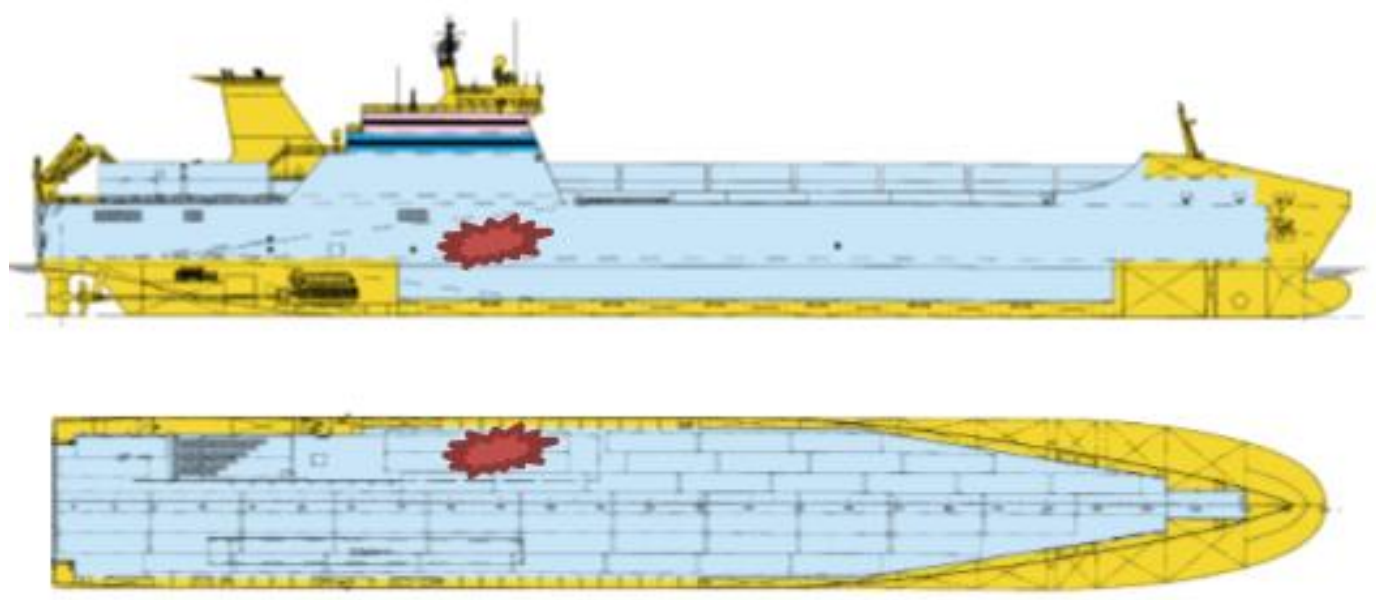

Fig. 1 Starting location of the fire 
Tug boats arrived at the scene at 10:00 and were trying to extinguish the fire. As the fire started inside the ship, there was no way of extinguishing it from the outside. However, tug boats continued to pour water on the ship's hull, bring down its temperature and prevent it from deformation. There were fears of an explosion if the fire was to reach the fuel tanks. Floating barrages were placed around the ship, but no oil leaked. One day after the fire, the ship was still burning, but the fire was under control and there was no threat of environmental disaster. A salvage crew from Rotterdam, whom were known for their role in the salvaging operations, was on board on February 8, after they controlled the fire completely the ship towed to port of Trieste [13]. When the salvaging operations were completed, MS UND ADRIYATIK was found to be totally damaged except all the machinery spaces such as pump room, steering room, and emergency generator room etc. Top deck was found to be melted and collapsed down. Whole steel structure of the ship was deformed because of high temperature. Because of the extensive damage, the owners requested the total constructive loss for the ship and the insurers approved.

\subsection{AHP method}

The AHP is a multi-criteria decision-making approach which can be used to solve complex judgement problems and it has attracted the interest mainly due to the mathematical properties of the method. The appropriate data are derived by using a set of pairwise comparisons. These comparisons are used to obtain the weights of importance of the decision criteria, and the relative performance measures of the alternatives in terms of each individual decision criterion. The mathematics of the AHP method is explained in numerous references $[14,15]$. In the pairwise comparison method, alternatives are presented in pairs. The alternatives are given by $\left\{A_{1}, A_{2}, \ldots, A_{n}\right\}, n$ is the number of compared alternatives, their current weights by $\left\{w_{1}, w_{2}, \ldots, w_{n}\right\}$, and the matrix of the ratios of all weights by,

$$
W=\left[\begin{array}{l}
w_{i} \\
w_{j}
\end{array}\right]=\left[\begin{array}{lllr}
w_{1} / w_{1} & w_{1} / w_{2} & \ldots & w_{1} / w_{n} \\
w_{2} / w_{1} & w_{2} / w_{2} & \ldots & w_{2} / w_{n} \\
\ldots & \ldots & \ldots & \ldots \\
w_{n} / w_{1} & w_{n} / w_{2} & \ldots & w_{n} / w_{m}
\end{array}\right]
$$

The matrix of pairwise comparisons $\mathrm{A}=\left[\mathrm{a}_{\mathrm{ij}}\right]$ represents the intensities of the questionnaire respondent's preference between individual pairs of alternatives ( $A_{i}$ versus $A_{j}$ for all $i, j=1,2, \ldots, n)$, chosen from a given scale. The scale for judgments in AHP method is given in Table 3. Given $n$ alternatives $\left\{A_{1}, A_{2}, \ldots, A_{n}\right\}$, the questionnaire respondent compares pairs of alternatives for all the possible pairs, and a comparison matrix $A$ is obtained, where the element $a_{i j}$ shows the preference weight of $A_{i}$ obtained by comparison $A_{j}$.

$$
A=\left[a_{i j}\right]=\left[\begin{array}{llllll}
1 & a_{12} & \ldots & a_{1 j} & \ldots & a_{1 n} \\
1 / a_{12} & 1 & \ldots & a_{2 j} & \ldots & a_{2 n} \\
1 / a_{1 j} & 1 / a_{2 j} & \ldots & a_{i j} & \ldots & a_{i n} \\
& & \ldots & & & \\
1 / a_{1 n} & 1 / a_{2 n} & \ldots & 1 / a_{i n} & \ldots & 1
\end{array}\right]
$$

If matrix $A$ is absolutely consistent, someone notice that $A=W$ and the principal eigenvalue is equal to $n$, i.e. $\lambda_{\max }=n$. The relations between the weights and the judgments defined by $w_{i} / w_{j}=a_{i j}$ for $i, j=1,2, \ldots, n$. The weights are obtained using the eigenvector method. If $A$ is an $n \times n$, primitive matrix, i.e. the matrix to be a nonnegative, irreducible matrix with a 
positive element on the main diagonal, then one of its eigenvalues $\lambda_{\max }$ is positive and greater than or equal to all other eigenvalues. There is a positive eigenvector $w$ corresponding to that eigenvalue:

$$
A w=\lambda_{\max } w
$$

where, $w$ is the weight vector. The eigenvector method for obtaining the weights in the AHP method yields a way of measuring the consistency of the questionnaire respondent's preferences arranged in the comparison matrix. If a pairwise comparison matrix is not consistent, two different situations may be considered; a contradictory matrix and a matrix neither totally consistent nor contradictory. The consistency index can be defined as

$$
C I=\frac{\lambda_{\max }-n}{n-1}
$$

Small changes in $\mathrm{a}_{\mathrm{ij}}$ imply small changes in $\lambda_{\max }$, with the difference between this and $n$ being a good measure of consistency. If the questionnaire respondent is completely consistent then, consistency index $C I=0$. However, it is principled to require $C I=0$. The $C I$ should use appropriately as Saaty proposed. The randomly generated reciprocal matrix using scale $(1 / 9,1 / 8, \ldots 1, \ldots, 8,9)$ and get the random consistency index to see if it is about $10 \%$ or less. If the order of the matrix is 9 , the $R I_{9}$ is taken as 1.45 [16]. In practice, it should be less than 0.1 . Dividing the $C I$ value by $R I_{9}=1.45$ one obtains $C R$ value. A value of $C R=0.1$ means that the judgements are $10 \%$ as inconsistent as if they had been given randomly. If the $C I$ greater than 0.1 than a correction of judgments is needed and the expert should revise his/her judgements until a value of CR smaller than 0.1 is reached [17].

Table 3 The scale for judgments in AHP method

\begin{tabular}{|l|l|}
\hline Scale & Judgments \\
\hline 1 & Equal \\
\hline 2 & Between Equal and Moderate \\
\hline 3 & Moderate \\
\hline 4 & Between Moderate and Strong \\
\hline 5 & Strong \\
\hline 6 & Between Strong and Very Strong \\
\hline 7 & Very Strong \\
\hline 8 & Between Very Strong and Extreme \\
\hline 9 & Extreme \\
\hline
\end{tabular}

\section{Case study background}

\subsection{Initial findings}

After the fire was extinguished, the deck was found covered by knee-deep ash and remnants in an almost indistinguishable state. There were no particular ignition sources to start a fire in the main deck other than the truck and the trailers. Trucks had some equipment which can be considered as potential igniters such as accumulators, electric and fuel connections. They also had other flammable items other than their cargoes such as the fuel storage tanks, tires, small butane/propane canisters and stoves for cooking, nylon covers, plastic and rubber components etc. 
Main and lower decks were the enclosed cargo spaces. Main deck which the fire began had a volume of about 35400 cubic meters. This kind of huge volume of air was able to provide the sufficient Oxygen which needs of a fire without any other air supply. Air fans of the main deck and the lower deck were kept to be off during the navigation and air intake was not permitted. However, the ship owner and operators used to prefer voyaging with ventilation closed but refreshing air during daytimes under good weather conditions. The fire on board was noticed to start next to the portside aft ramp of the main deck which was also loaded with trucks on it. The air intake of the machinery room main ventilation fan was close to the fire scene and located on the inboard wall about 1 meter just above the vehicle ramp between the main deck and upper deck.

Anti-skid arrangement on the fixed ramp was made of a thick coating of epoxy based anti-skid paint. Although there was no fire in the machinery room, it filled with smoke in a short time and main engines and auxiliaries stopped shortly afterwards due to the lack of the Oxygen. The RoRo decks were controlled by the smoke detectors and equipped with a manually activated spray drencher system to respond to a possible fire in the enclosed decks. In order to operate the drencher system; the chief officer need to enter the safety control room to open the master butterfly valve and some diverter valves through the grouped spray nozzles located in cargo spaces, manually and electro-hydraulically. The spray pump could be started from the bridge, the emergency room or cargo control room as well as the safety control room. All fire pumps included the spray pump were equipped with a hydraulic valve/actuators to supply a steady flow during start up periods. When the pump was once started, the actuator gradually opened the discharge valves and its opening ratio was also monitored. Electrical fire pumps were equipped with an air-vacuum pump for priming on it. However, during the fire, these pumps stopped when the electric supply ceased due to the stopping of diesel generators in the machinery room and could not re-start later with the emergency diesel generator. All people on board were required to use the open deck passage on port side in order to reach the lifeboats from the muster-station. The passage was only a few meters high on the upper deck which is above the main deck. The passage to lifeboats and life-rafts was unprotected, so the escape route to survival crafts were blocked by fire and smoke.

\subsection{Possible factors for the fire on board}

The possible reasons for the accident were determined by discussing it with the sea captains, chief engineers, technical and P\&I Club surveyors, and safety engineers:

1. Anti-skid coating paint: The anti-skid coatings produced a heavy smoke during fire and this smoke caused zero-visibility in the cargo department. In addition, because of the place of the suction side of ventilating air entrance, this heavy smoke entered the engine room, and it was the reason of insufficient Oxygen for ICEs.

2. Place of the suction side of ventilating fan intake of the engine room: The ventilating fans are located just side of the aft ramp of the main deck. If those fans were placed another dwelling, the engine room did not fill up with heavy smoke.

3. Lack of education and training of crew: While examining the case and the development of events, it is possible to speak of a serious lack of education and training is examined. Under normal circumstances, though, the crew of the ship against such an emergency situation would not be expected to get caught so unprepared. 
4. Risky materials that trucks carried on board: Butane/propane canisters and stoves used for drivers' personal cooking are transported in trucks. And these canisters pose a serious risk to on board fire on ships.

5. The lack of usage of A-60 insulation on walls and decks: Isolating against the fire needs the usage of A-60 insulation on walls and decks. The requirements in SOLAS regulations II-2/9 specifies that the "divisions separating RoRo spaces need to be steel or equivalent material but is not required to be of " $A$ " class standard". Cargo decks in MS UND ADRIYATIK are separated from each other by steel construction without any fire integrity value except for the machinery room wall at main deck. It is not obligatory to use A-60 insulation on walls and decks. But, if it was used, the catastrophic fire could not have build up.

6. Lack of CCTV arrangement: If there was a video surveillance or CCTV system on board, the fire could be visible in advance. Necessary precautions against on board fire could be taken without delay.

7. Delay in the response to the fire: For a variety of reasons (training of the crew, human habits and behaviour, etc.), delay in the response to the fire enlarged it and unable to control.

8. Installation logic of fire pumping lines: Fire extinguishing pipes are way too long around the ship. Water reaches the decks to be delayed intervention. Also, if the fire on board trainings were done regularly and completely, the crew know about the delay, and they would not leave their places.

9. Priming problem of air vacuum pump, fire hose and the sprinkler system: Since there is lack of Oxygen in the Engine Room, the air vacuum pump could not prime so the sprinkler system could not started. Due to the human behaviour factor, the crew avoid to activate the drencher system manually because of the undesirable consequences of the sea water.

\section{Results}

In order to prevent fire on board in ships; sea captains, chief engineers, technical and P\&I Club surveyors, and safety engineers working for 3 years or more were interviewed and surveyed. All of the 26 experts were male. The application of the AHP technique to the study case was performed using the Microsoft Excel. Nine reasons were determined for each cause of the fire. The purpose of this survey was to determine the order of importance of the reasons and recommendations to be taken. The survey form is given in Appendix. When filling out the survey, they were asked to rate the relative importance of each item against the others in the reasons listed in each group. For each item, the left side is compared against the right side. If a number on the right side is selected, as in the first line, it weighs more importance to the item on the right. On the other hand, if the number on the left is selected, it weighs more importance to the item on the left. Finally, if it is given unity, both items are equally important. The scale for judgments is shown in Table 3. Fire on board reasons and priorities, and ranks of the considered alternatives according to AHP technique given in Table 4 is arranged from the highest priority (rank 1) to the lowest priority (rank 9). The consistency index $C I$ is less than $0.1(C I=0.088)$, so no correction of judgments is needed. 
Table 4 Fire on board reasons and priorities

\begin{tabular}{|c|c|c|}
\hline On board fire reasons & AHP & Rank \\
\hline Lack of education and training of crew & 0.25 & 1 \\
\hline Place of the suction side of ventilating air entrance & 0.21 & 2 \\
\hline Lack of CCTV arrangement & 0.14 & 3 \\
\hline Anti-skid coatings & 0.11 & 4 \\
\hline Delay in the response to the fire & 0.07 & 5 \\
\hline Risky materials that trucks carried on board & 0.06 & 6 \\
\hline The lack of usage of A-60 insulation on walls and decks & 0.06 & 7 \\
\hline Installation logic of fire pumping lines & 0.05 & 8 \\
\hline Priming problem of air vacuum pump, fire hose and the sprinkler system & 0.05 & 9 \\
\hline
\end{tabular}

\section{Conclusions and recommendations}

This paper investigates the marine fires with exercising a specific example, MS UND ADRIYATIK fire and examines why and how the fire could not be controlled nor extinguished. It was carried out by analysing the results of a questionnaire appropriate for the AHP technique. Twenty-six experts were surveyed. The purpose of this survey is to determine the order of possible explanations for this fire accident and possible provisions and precautions to be taken.

The ship designers certainly must consider the hazards in the future design when it is used or operated in the intended manner. A hazard is any aspect of technology or activity that produces risk or danger of injury. The designers must also recognize that the product may be used in unintended but foreseeable ways. Protection must be provided against hazards in all uses that can be foreseen by the designer. Unfortunately, even the most meticulous search for foreseeable uses may still leave a mode of use undiscovered.

A water-lift system will be a good solution to prevent siphoning through the raw water pump even if the engine is stopped. In a block-out situation (dead ship condition), in which the main engine and generators are out of action, the power required for the fire fighting pumps must be supplied by external batteries.

Port States should check more frequently and rigorously the issuer of the seafarers' certificate and training. So the capacity and reliability of the seafarers will increase in a positive way. Ship owners should check themselves in agreement with independent organizations for these controls. A safety culture should be some how gained by seafarers.

Ship owners want to load more trucks to RoRo vessels, so the gaps in the truck parking lanes are decreasing. This makes it difficult to reach the place of fire personnel in the event of a possible fire hazard and to intervene in time. Ship designers should consider this fact while designing RoRo vessels. 
It is difficult for the flame detectors to detect the flame on time because of the height of the trucks. Smoke detectors can also detect fire, but it can cause some delays. Thus, the detectors must be in their precise and optimized places. In addition, CCTV facilities would offer the clear view of the exact escape route and wide-angle of surveillance.

Circuit lines from the fire pumps at lower decks to sprinkler systems or to fire cabinets should be as short as possible for reduce the travel time of water along the line. Furthermore, they should be separated for starboard side and port side, yet should be endorsed each other.

At the beginning, it takes a significant time to reach the water in fire cabinets because of no sea water at lines. Whenever the system activated, the air exhausts from the fire hose, at first. In case of disregarding the training schedules and procedures, some crew members trying to fight to fire can leave their duty and positions and begin to escape in panic, because of the late water ejection. Therefore, the firefighting lines through the fire cabinet need to attract the designer's special attention.

Suction sides of the ventilating fans for machinery spaces are not to be headed to the cargo areas. Because, especially during loading and unloading of cargo, the polluted air (exhaust mixture) are available. In addition, the heavy smoke due the non-slippery coating materials on ramp surface or any truck fire case in cargo areas will immediately fill the engine room. In this example, the ventilation fans were replaced near by the ramp on cargo area, so it is concluded as an erroneous design choice.

It is an unexpected fact that priming problem of air vacuum pump, fire hose and the sprinkler system is ranked so low. If these systems operated functionally on time, the fire would be extinguished without major damages. For easy firefighting, both on the port and starboard sides, an integrated fire pump and sprinkler system should be placed every 50 meters. The sprinkler system automatically must be activated a few minutes later after fire alarms is on or it should start the water injection after resetting the fire alarm manually, once more time.

Ship owners' active role is essential in the prevention of on board fire accidents, both in discovering and improving the safety issues. However, ensuring a safe work environment on board often costs money. There are many precautions of reducing risk of on board fire accidents, including safety training. The success of preventing and reducing risk of on board fire accidents depends on continuous implementation of protective actions and inspection. To increase safety awareness among crew, safety culture must be somehow gained. Strength of supervision and adjustment of safety management policy are needed to decrease the risks. The seafarers should be guided and supervised.

\section{Acknowledgements}

The authors would like to thank the experts who spare their time to complete the questionnaire. 


\section{REFERENCES}

[1] GISIS, 2015. Maritime Casualty and Incidents, Global Integrated Shipping Information System. http://gisis.imo.org (accessed: 14.12.2015).

[2] Chen, S-T., Wall, A., Davies, P., Yang, Z., Wang, J., Chou, Y-H., 2013. A Human and Organisational Factors (HOFs) Analysis Method for Marine Casualties Using HFACS-Maritime Accidents (HFACSMA). Safety Science, 60, 105-114. https://doi.org/10.1016/j.ssci.2013.06.009.

[3] Oltedal, H., Wadsworth, E., 2010. Risk Perception in The Norwegian Shipping Industry and Identification of Influencing Factors. Marit. Pol. Mgmt., 37 (6), 601-623. https://doi.org/10.1080/03088839.2010.514954.

[4] Hassel, M., Asbjørnslett, B.E., Hole, L.P., 2011. Underreporting of Maritime Accidents to Vessel Accident Databases. Accident Analysis and Prevention, 43, 2053-2063.

https://doi.org/10.1016/j.aap.2011.05.027.

[5] Macrae, C., 2009. Human Factors at Sea: Common Patterns of Error in Groundings and Collisions. Marit. Pol. Mgmt., 36 (1), 21-38. https://doi.org/10.1080/03088830802652262.

[6] Arslan, O., Turan, O., 2009. Analytical Investigation of Marine Casualties at the Strait of Istanbul with SWOT-AHP Method. Marit. Pol. Mgmt., 36 (2), 131-145. https://doi.org/10.1080/03088830902868081.

[7] Kang, I-K., Kim, H-S., Kim, J-C., Park, B-S., Ham, S-J., Oh, I-H., 2013. Study on The Marine Casualties in Korea, J. Kor. Soc. Fish. Tech., 49 (1), 29 -39. https://doi.org/10.3796/KSFT.2013.49.1.029.

[8] Schröder-Hinrichs, J.U., Baldauf, M., Ghirxi, K.T., 2011. Accident Investigation Reporting Deficiencies Related to Organizational Factors in Machinery Space Fires and Explosions. Accident Analysis and Prevention, 43, 1187-1196. https://doi.org/10.1016/j.aap.2010.12.033.

[9] Dutta, B.B., Kar, A.R., 2009. Simulation Techniques for Ship Onboard Fire Safety. Proceedings of the ASME 28th International Conference on Ocean, Offshore and Arctic Engineering, OMAE2009, May 31 June 5, 2009, Honolulu, Hawaii, pp: 1-6. https://doi.org/10.1115/OMAE2009-79911.

[10] Wang, L., Su, S., 2011. Three-dimensional Numerical Simulation of Smoke Motion in Fire of the Ship Engine Room with Multilayer Structure, Brodogradnja, 62(4), 366-372.

[11] IMO, 2015. International Maritime Dangerous Goods (IMDG) Code. http://www.imo.org/OurWork/Safety/Cargoes/Pages/DangerousGoods.aspx (accessed: 17.12.2015).

[12] Undersecretariat for Maritime Affairs, 2008. Report On The Investigation of The Fire On Board UND ADRIYATIK, Marine Accident Investigation Commision, Republic of Turkey, Undersecretariat for Maritime Affairs, General Directorate of Maritime Transport, 6 February 2008, Ankara.

[13] Smit, 2014. http://www.smit.com/projects/project/und-adriyatik.html, (accessed: 19.12.2014).

[14] Saaty, T.L., 2003. Decision-Making with The AHP: Why Is The Principal Eigenvector Necessary. European Journal of Operational Research, 145, 85-91. https://doi.org/10.1016/S0377-2217(02)00227-8.

[15] Alonso, J.A., Lamata, M.T., 2006. Consistency in the Analytic Hierarchy Process: A New Approach. International Journal of Uncertainty, Fuzziness and Knowledge-Based Systems, 14(4), 445-459. https://doi.org/10.1142/S0218488506004114

[16] Saaty, T.L., 1980. The Analytic Hierarchy Process, McGraw-Hill Publications, New York.

[17] Brunelli, M., 2015. Introduction to the Analytic Hierarchy Process, Springer, London. https://doi.org/10.1007/978-3-319-12502-2.

Submitted: $\quad$ 21.12.2016. $\quad$ Baris BARLAS, barlas@itu.edu.tr Reyhan OZSOYSAL, reyhanoz@itu.edu.tr

Accepted: $\quad$ 12.09.2017. $\quad$ Ertekin BAYRAKTARKATAL, bayrak@itu.edu.tr Osman A. OZSOYSAL, ozsoysal@itu.edu.tr Istanbul Technical University, Faculty of Naval Architecture and Ocean Engineering, Naval Architecture and Marine Engineering Department Maslak 34469, Sariyer, Istanbul, Turkey. 


\section{Appendix}

\section{The Case}

MS UND ADRIYATIK caught fire on the early morning hours of February 6, 2008, 13 nautical miles off the coast of Istria, Croatia, just outside Croatian territorial waters. An SOS was launched at 04:04 local time. It said that the ship was sailing from Istanbul to Trieste and was carrying 200 trucks and nine tons of dangerous material, in addition to between 100 and 200 tons of ship fuel, causing fears of environmental damage. Then, the ship's 22 crew members and nine passengers were rescued by the Greek ship Ikarus Palace that was sailing nearby.

The progress of events are abstracted from independent expertise reports, witness statements and court papers. MS UND ADRIYATIK departed from its terminal in Istanbul on 03 February 2008 to her destination Trieste with 22 crew and 9 passengers (truck drivers) on board. She carried 200 trucks and trailers, which were stowed and secured in her 4 decks. Trucks carrying International Maritime Dangerous Goods (IMDG) Code Class 4.1 and 3 type dangerous cargoes were stowed on the upper deck in accordance with certificate for carriage of dangerous goods. Neither the vehicles with refrigeration plants were stowed in the closed decks. Trucks with electrically-driven refrigeration plants were stowed at upper deck, and trucks with separate diesel engine used to driven reefer units were stowed at top deck. There were no particular ignition sources to start a fire in cargo decks other than the trucks and the trailers. There were about 60 trucks and trailers on the main deck, all of them with batteries, diesel fuel, flammable objects, butane/propane canisters and stoves for cooking etc. After departing from terminal, as a standard procedure, the outer ventilation and ventilation dampers were closed. The voyage was ordinary until about 05:30 hours (ship time) in the early morning of 06 February 2008, just 3 hours before arrival at her arranged destination port of Trieste.

The chief officer started his watch on 04:00 hours as usual. There was also a watchman at the bridge. The weather was N/NE 3 Beaufort, sea state was 2 and visibility was good. Steering gear was in automatic pilot mode. At around 05:30 hours, a fire alarm went on by the automatic fire detection system, and the fire detecting and alarm system panel on the bridge indicated the fire at the 14th and 15th smoke detector loops for main deck. The smoke detectors denoted the fire signals coming from the vehicle ramp at the port side of main deck through the upper deck. The mentioned section was controlled by the Deluge Sprinkler system zone 6 and 7. A Deluge Sprinkler system is a fixed fire protection system in which the pipe system is empty until the deluge valve operates to distribute pressurized water from sprinklers. The chief officer silenced the alarm. When the alarm is in silenced mode, the lights stay on for the zones but the sound is off. The chief officer need to check if the alarm is real or fake, and he reset the alarm system. Alarms system immediately reproduced the fire alarm signal after resetting. The chief officer described the fire zone to the watchman near him and directed him to check the position of fire on the main deck. The chief officer then reset the alarm system for the second time while waiting the watchman and he noticed the alarm signal was still sounding. The chief officer called the bosun -a ship's officer in charge of equipment and the crew- by phone and sent him to control the fire zone. The watchman went down to the main deck through the stairs in the accommodation area and opened the watertight door with the help of the bosun which is kept closed all the time during the journey. The crew entering the main deck area saw that the trucks parked on the second and third lanes on the port side were burning and visibility due to heavy smoke was too short. The bosun reported the fire on the main deck by phone to the chief officer, then both the bosun and the watchman left the fire 
area immediately as they were not equipped with any protective of firefighting equipment. Then, the chief officer immediately waked up the Captain, and the Captain arrived at the bridge shortly afterwards, the time was 05:48, the general alarm was activated. The chief officer informed all on board with two announcements from the ship announcing system and called them to summon on the muster-station -the place on the ship where crew should assemble in the event of an emergency- to fight the fire. The Captain transmitted a distress call by VHF radio at 06:04. The firefighting team finalized their preparations about 7 minutes and went down to the watertight door of the main deck, however, only two seafarer could just be equipped with firefighting suits, the other crew members had no protective equipment. Several minutes were lost during the preparation of the life safety rope. Afterwards, the machinery and deck teams entered into the fire scene. Team who took the fire hose proceed into the fire scene for about 5 to 10 meters under conditions of thick smoke. The fire hose puffed-up but air was discharging instead of water. No water was coming from the hose. The team noticed that the second and third trucks just from the sliding door towards the fore-port part was in flames. The smoke was getting thicker and a panic was growing by the time. Afterwards the Captain at the bridge ordered to the third officer to start the sprinkler pump and the emergency fire pump right after the report from the firefighting team. But this was another non-useful solution just like the fire hose trial, because the water was not sprayed from the sprinklers. The firefighting team members without protective equipment were badly affected. After a while, the firefighting team members figured out that it was of no use without water and decided to leave the scene, failed to control and extinguish the fire. Fire, heat and smoke in the aft upper deck blocked access to survival craft and all on board were trapped in the bridge area. They managed to escape to the forecastle by descending down from the forward wall of accommodation using fire hoses and flag lanyards. After 15 minutes, the Captain had to give the order to abandon the ship as the fire approached dangerously close. All crew and passengers were rescued by about 07:00. Tug boats arrived at the scene at 10:00 and were trying to extinguish the fire. As the fire started inside the ship, there was no way of extinguishing it from the outside. However, tug boats continued to pour water on the ship's hull, bring down its temperature and prevent it from deformation. There were fears of an explosion if the fire was to reach the fuel tanks. Floating barrages were placed around the ship, but no oil leaked. One day after the fire, the ship was still burning, but the fire was under control and there was no threat of environmental disaster. A salvage crew, whom were known for their role in the salvaging operations, (from Rotterdam) was on board on February 8, after they controlled the fire (extinguished the blaze) completely the ship towed to port of Trieste.

\section{The possible reasons for the accident:}

1. Anti-skid coating paint,

2. Place of the suction side of ventilating fan intake of the engine room,

3. Lack of education and training of crew,

4. Risky materials that trucks carried on board,

5. The lack of usage of A-60 insulation on walls and decks,

6. Lack of CCTV arrangement,

7. Delay in the response to the fire,

8. Installation logic of fire pumping lines,

9. Priming problem of air vacuum pump, fire hose and the sprinkler system. 
A Study on the Identification of Fire Hazards on Board

Baris BARLAS, Reyhan OZSOYSAL, A Case Study Ertekin BAYRAKTARKATAL, Osman A. OZSOYSAL

Table: The expert questionnaire for the accident.

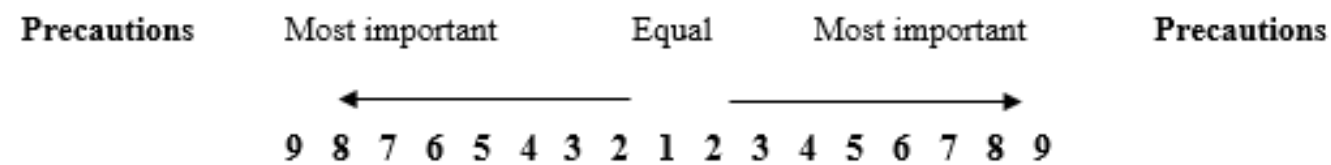

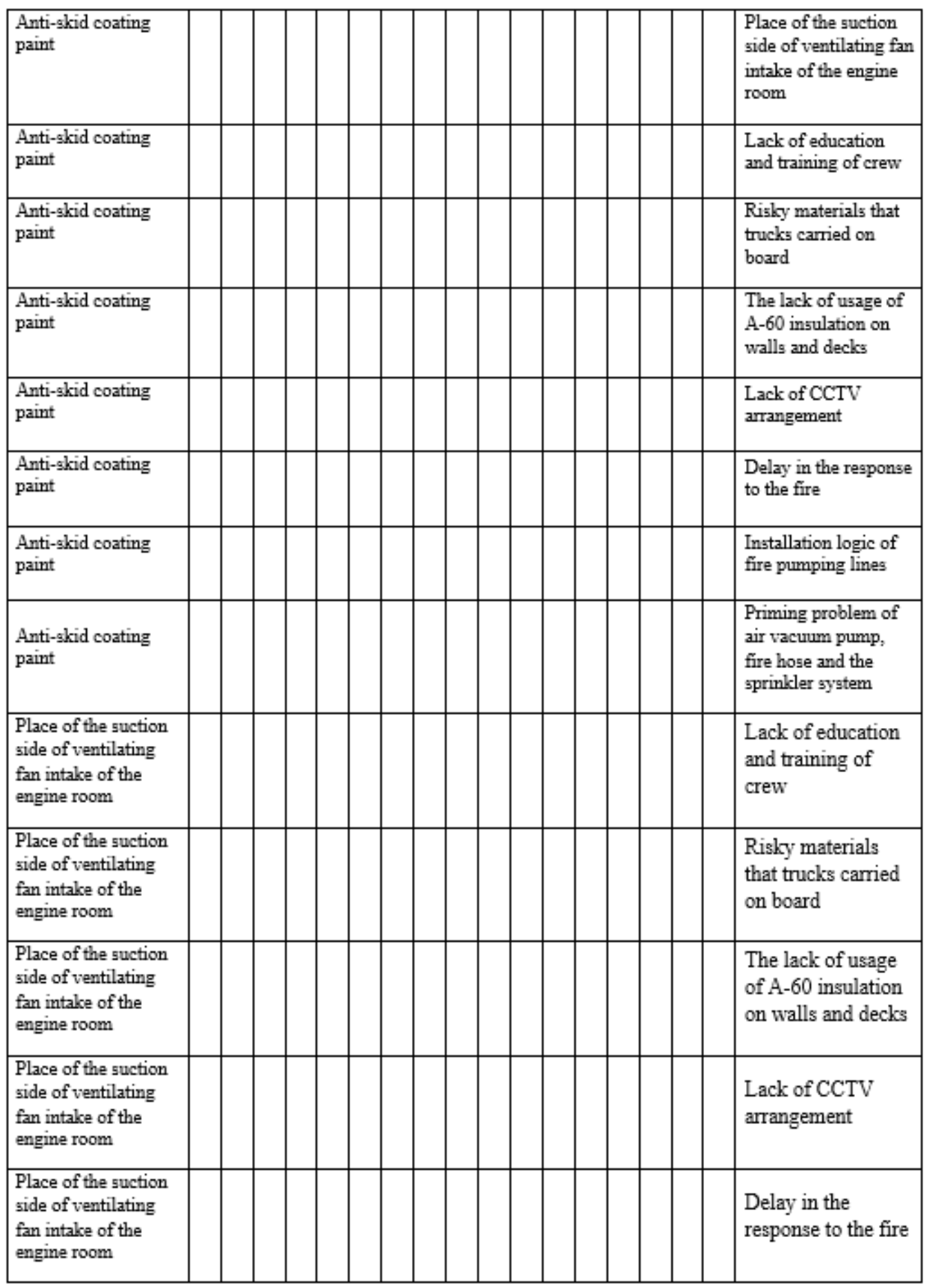


$\begin{array}{lllllllllllllllll}9 & 8 & 7 & 6 & 5 & 4 & 3 & 2 & 1 & 2 & 3 & 4 & 5 & 6 & 7 & 8 & 9\end{array}$

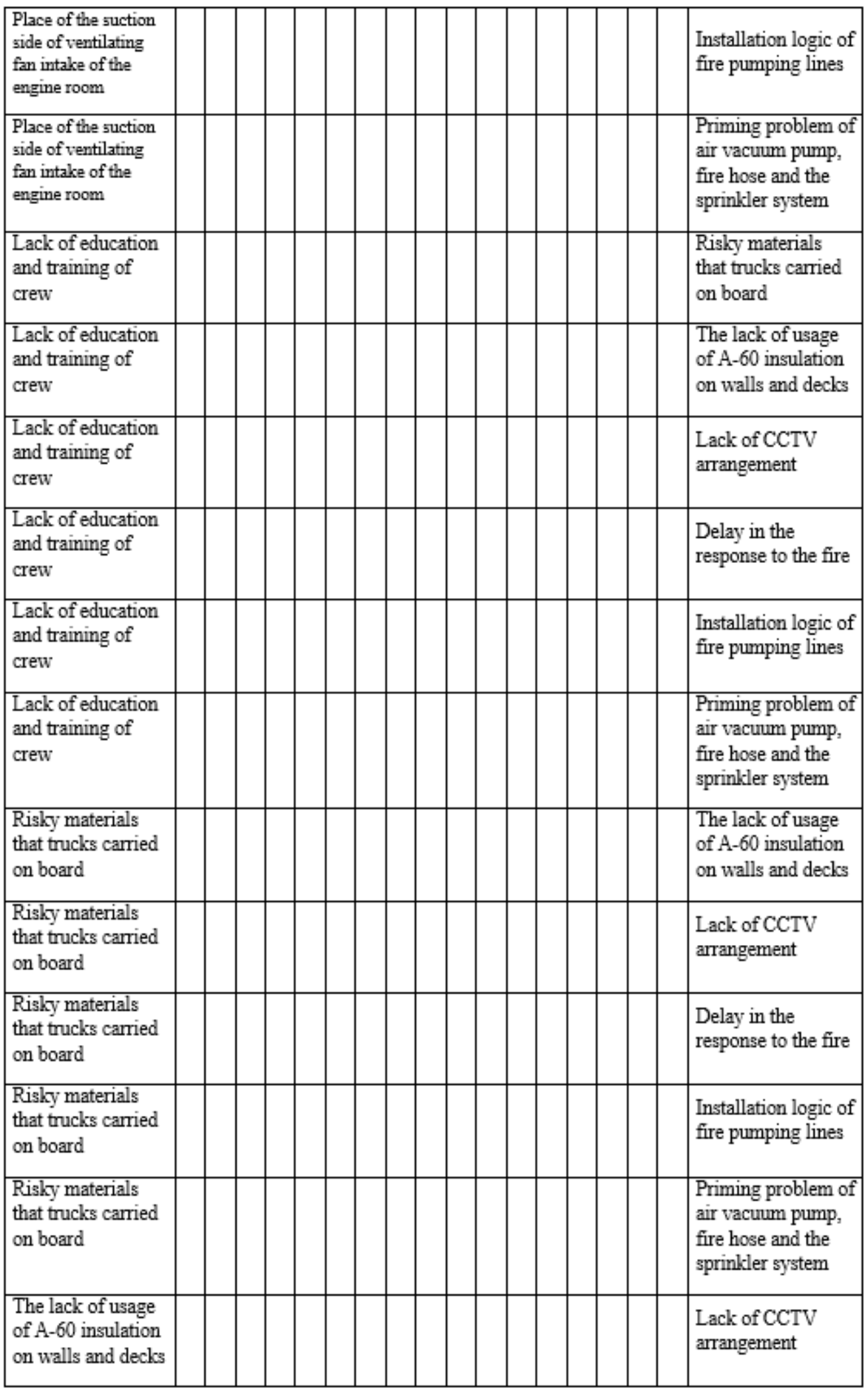


$\begin{array}{lllllllllllllllll}9 & 8 & 7 & 6 & 5 & 4 & 3 & 2 & 1 & 2 & 3 & 4 & 5 & 6 & 7 & 8 & 9\end{array}$

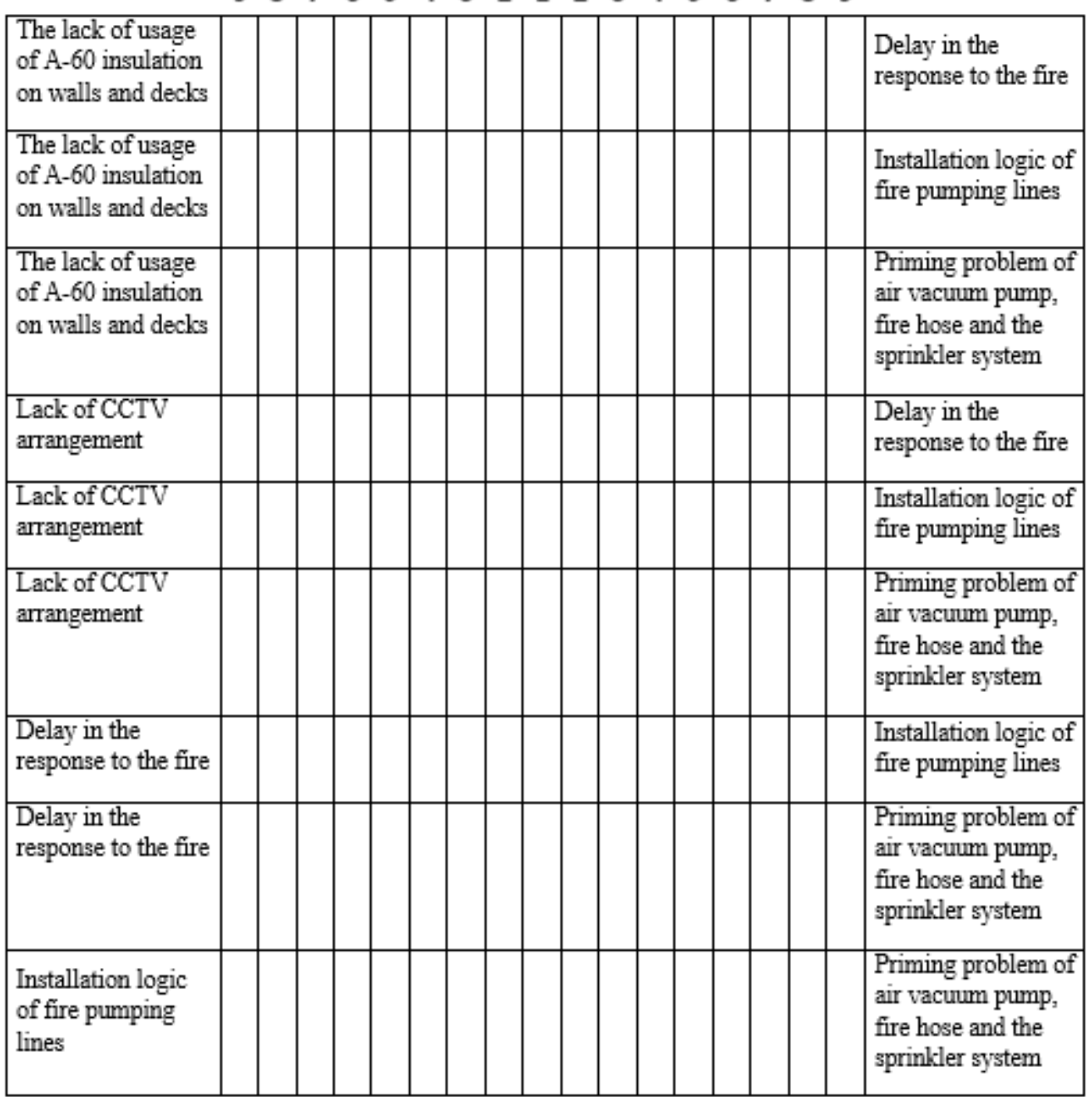

